end of five weeks was completed and the aneurysm cured, a large, hard, non-pulsating mass remaining in the popliteal space. Having now returned to duty I determined to undertake the treatment of the right aneurysm by the method with which my own name is associated in surgical writings, and which consists in locking up the blood in the aneurysmal cavity by means of elastic appliances sufficiently long for its coagulation en masse, and not by the deposition of fibrinated laminæ as usually follows treatment by ligature or slow pressure. I began by keeping the patient at rest for a few days on a light non-stimulating diet. Iodide of potassinm was also administered with the view of increasing the plasticity of the blood. Carte's tourniquet was occasionally applied to the femoral for the purpose of opening up the collateral circulation preparatory to the occlusion of the vessel by the rapid consolidation of the aneurysm. On Oct. 3rd, the patient consenting to take chloroform if necessary. I carried out the method originally described by myself, ${ }^{1}$ using in addition a protector over the aneurysm so as to take the pressure of the elastic bandage. This was made of gutta. percha so as to cover the tamour in the popliteal space with the joint somewhat flexed, and sufficiently strong to protect it effectually from direct pressure. I now applied an elastic bandage firmly and evenly from the toes upwards and over the protected aneurysm to the level of the middle third of the thigh. Here a soft elastic constrictor was secured over several turns of a flannel bandage. The elastic bandage and protector were now removed, whilst the constrictor was kept in position. The blood was thus locked up in the aneurysmal cavity, whilst the rest of the limb below the constrictor remained bloodless. It is important to render the limb bloodless in this way, as otherwise coagula might form in the veins and smailer arteries during the arrest of the circulation by the constrictor. Were they to do so there might be a risk of their interfering seriously with the circulation through the limb after the main vessel has become obstructed by the rapid consolidation of the aneurysm, and the blood-supply bas to be passed down by the collateral branches with diminished force. The patient was now covered with warm blankets, the limb being semi-flexed and the elastic constrictor remaining in position. He complained of no pain during the first forty-five minutes; after this he began to feel much distressed, but preferred to do without chloroform. At the end of an hour-the aneurysm being then hard, solid, and decidedly smaller-I carefully adjusted a Carte's tourniquet upon the femoral, and removed the constrictor and flannel bandage; but about five hours afterwards on easing off the tourniquet a pulsation (faint, tremulous, and at times hardly perceptible) was felt in the aneurysm. This symptom occurriog at this stage has been noted in other cases treated by the same method, and was referred to by Mr. Pearce Gould in an interesting raper read by him at the International Medical Congress in 1881, when this mode of treating aneurysm was discussed. Mr. Pearce Gould explains its occurrence by the clot contracting more rapidly than the sac upon it, thus leaving a space between the two, which after a time becomes filled either by the deposition of fibrin or by further contraction of the sac. In the present case it ceased after five days, and the vessel became occluded in the lower part of Hunter's canal. It is instructive at the date in which I write to observe the conditions arising from the treatment of these two aneurysms in the same patient by methods differing essentially from each other in principle. In the left one, treated by slow and intermittent pressuse, which aims at consolidation by the gradual deposition of fibrinated laminæ in the cavity of the aneurysm, the remains now form a hard, unyielding lump in the popliteal space, cansing a good deal of discomfort to the patient and interference with the use of the limb. It must be some time before this mass of fibrin can be absorbed to any extent and cease to trouble the patient. On the other hand, in the right aneurysm, treated by a plan which aims at the rapid formation of an ordinary blood-clot in the aneurysmal cavity, the soft material has contracted as well as the sac which encloses it, so that there is only a small mass left in the floor of the popliteal space, which can hardly be distinguished by the observer and is not felt by the patient in any way. Another point of difference in the results is that in the left limb, treated by the slow method, no pulsation can be felt in the femoral artery below the origin of its deep branch in the groin, whilst in the right limb the femoral can be felt pulsating in the lower part of Hunter's canal. In my original case, in which the patient died eight months after cure from other causes, I had an opportunity of examining and making a preparation of the parts. This preparation is now in Haslar Museum and shows that the ressel is only occluded for about two and a balf inches of its course. ${ }^{2}$ It would appear, then, from these two cases that when this plan of treating popliteal aneurysm is successful the circulation is brought down through the main ressel of the limb and becomes finally arrested only a short distance from the aneurysm, as if, in fact, the latter were cut out and the vessel tied.

Haslar.

\section{THE CONDITION OF THE BLOOD IN THE} CYANOSIS OF CONGENITAL HEART DISEASE. 1

Br G. A. GIBSON, M.D., D.Sc. Edin.,

PITSICIAN fTO THE DEACONESS HOSPITAL; ASSISTANT PHYSICIAY TO THE ROYAL INFLRMARY; LECTURER ON MEDICLNE AT MINTO HOUSE, EDINBURGF.

Notwithstanding the numerous works published within recent years on the state of the blood in disease, we nevertheless not only need information as to the changes which it undergoes in a great variety of different conditions, but we also require explanations to account for many of the altera. tions which are generally recognised. This is the case even in regard to some of the affections met with in every-day practice ; in the disturbances of the circulation produced by valvular diseases, for example, there are some modifications of the blood of common occurrence, but as yet insufficiently known and inadequately explained. More particularly is this true of the state of the blood in the cyanosis of congenital heart disease, which presents changes which bave from time to time been recorded, but have not yet received satisfactory elucidation. A most interesting case of congenital disease of the heart has lately been for some time under my observation, and from the clinical features presented by the patient some conclusions have been forced upon me to which attention will in this paper be briefly directed.

A boy aged eight years was admitted to the Deaconess Hospital on Oct. 25th, 1894, complaining of breathlessness on exertion. Both parents were alive and had always been healthy; he was one of a family of eleven, of whose members two sons had died, one from scarlet fever and another from hydrocephalus, but the remaining six sons and two danghters were in good health. At the time of his birth the parient was apparently a healthy infant, but when a few months old he became bluish in colour and had always since been delicate. He had an attack of scarlet fever some years ago from which he recovered perfectly. On admission he was observed to be deeply cyanosed; the skin everywhere was of a bluish tint, the lips were almost black, and the conjunotivæ were dusky. The fingers and toes were markedly clubbed, and the nails, which were much curved, were almrst black. The patient was 3ft. 9in. in height, and weigbed 2st. 10lb. The temperature was below normal, but has fluctuated between $97^{\circ}$ and $99^{\circ} \mathrm{F}$. The alimentary system showed no symptoms of disturbance. The second dentition was in progress. The tongue was clean, but of a very dark purple colour. The liver exactly reached the costal margin in the right mammillary line. The hæmopoietic system presented some interesting facts. The spleen reached to the mid-axillary line, and was therefore of the usual size. On examination of the blood with the hæmoglobinometer the hæmoglobin was found to be 110 per cent. With the Thoma-Zeiss bæmocytometer the red corpuscles were seen to be $8,470,000$ per cubic millimetre, while the white corpuscles numbered 12,000 . The spectroscope showed the characteristic double band of oxyhæmoglobin. With regard to the circulatory system, the patient on any exertion became much more cyanosed and panted violently, but when lying quietly in bed showed much less cyanosis and almost no breathlessness. On inspection there was no visible pulsation in the neck, and in the precordial region there was no impulse save the apex 
beat in the fifth left intercostal space. The pulse varied from 64 to 114 . The vessel was rather empty, the pressure low, and the pulsation regular. No thrill was felt in the precordia, but an impulse with both systole and diastole, and the apex-beat was determined to be one inch and threequarters from the mid-sternum. On percussion the borders of the cardiac dulness were found at the level of the fourth costal cartilages to be one inch and a half to the right and two inches and a half to the left of 'the mid-sternal line. A lond rasping murmur was heard over the entire precordia its maximum intensity was at the left edge of the sternum at the level of the fourth costal cartilage, and it was propagated upwards as far as the external ends of both clavicles-to the right as far as the mammilla, to the left four inches beyond the mammilla and downwards along each costal margin to the same extent- $-\mathrm{viz}$., two inches and a half below the level of the xiphoid cartilage. No murmur could be heard in any ressel. The thorax was distinctly pigeonbreasted. There were numerous 1honchi throughout the chest, but otherwise the respiratory system presented no symptoms requiring notice. The respirations numbered 24 per minute. The urine was pale in colour and acid in reaction; its specific gravity was 1022. It contained no abnormal constituents. The integumentary system was, apart from the high degree of cyanosis, not distinguished by any special characters, and the nervous system was in all respects normal. Although the patient had never been taught, on account of his state of health, he was an intelligent and observant boy, al ways enjoying high spirits.

The diagnosis of the cardiac lesion was attended by some difficulty. There could be no doubt that the condition was congenital, for although the cyanosis onjy showed itself after the lapse of some months from the date of birth, the patient had not during the interval suffered from any acnte disease capable of causing endocarditis. In this respect the history of the case is in accord with that of most congenital heart lesions. The maximum intensity of the murmur being almost in the tricuspid area might favour the view that there was regurgitation at the right anriculo-ventricular orifice; but such an explanation is negatived by the absence of any venous symptoms in the neck. On the other hand, the murmur might be produced by obstruction at the pulmonary orifice, and heard with greatest intensity over a dilated and hypertrophied right ventricle, such as undeniably is present in the case ; or, again, the murmur might be the result of a communication between the two ventricies, caused by a perforate septum ventriculorum, allowing a stream of blood to flow from the left cavity into the right, and thus to produce over the right ventricle a systolic murmur. The lesions probably present, judging not only from the clinical facts of this case, but also from the experience of similar cases, are some obstruction at the pulmonary orifice and an imperfect ventricular septum. Such is the provisional diagnosis of the case.

Attention must now be given to the condition of the blocd. As has been stated in the brief abstract of the case, the amount of brmoglobin was 110 per cent., and the number of the hæmocytes and leucocytes respectively $8,470,000$ and 12,000 per cubic millimetre. In another patient, a boy aged two years and four months, suffering from congenital heart disease (for the opportunity of observing whom my thanks are due to Dr. John Thomson), the hæmoglobin was 92 per cent, the red corpascles numbered 6,700,000 and the white corpuscles 12,000 per c.mm. The number of the blood corpuscles in congenital diseases of the heart appears to have been first observed by Toeniessen, who found in a girl aged ten years, with congenital pulmonary stenosis, 7540000 hæmocytes, and in a boy aged thirteen years, suffering from the same affection, 8,820,000 per c. mm. Since his observations similar facts have from time to time been placed on record. Carmichael, for example, in publishirg a most interesting case of congenital heart disease recently. states that the patient had $8,100,000$ red corpuscles and 16,000 white corpuscles per c.mm.

Now, before entering upon the question as to how such an increase can be produced, it may be well to recall the two diverse explanations of cyanosis-the one, that of venous stasis, originating with Morgagni ; the other, that of a mixture of the arterial and the venons blood, suggested by Hunter. Both theories have been supported by numerous observers from the time of their inception until the present day, but the preponderance of opinion is in favour of the theory of Morgagni. The riew of Hunter may be said to be negatived by the simp? e facts that in many cases permitting the mixture of arterial and venous blood there is no cyanosis, and that in many cases of cyanosis there is no possibility of the mingling of venous and arterial blood. Starting with the conception that cyanosis is produced by obstruction to the circulation and venous stasis, the question now arises why this condition should be associated with an increase in the number of the blood-corpuscles. It is not only in the cyanosis of congenital lesions that the increase is found, but in all cases where cyanosis is really present on account of failure of the circulation. To this point Toeniessen and Schneider have particularly called attention, and of the accuracy of the observation any one can convince himself by investigation of the blood. The work of Malassez seems to show that the blood in the superficial parts of the body contains a larger number of red corpuscles than that from the deeper layers, and Penzoldt and Toeniessen believe that this increase is caused by the loss of flaid from the surface. while the blood of the interior is constantly receiving fluid from the alimentary canal. Eren if this be correct, it cannot be accepted as an explanation of the great increase in the number of the corpuscles found in cyanosis, as it would involve the postulate that in some cases where the number of corpuscles is nearly doubled, the quantity of the fluids of the blood must be reduced nearly to one-half. Cohnheim's celebrated experiment of tying the crural vein of the frog, which is followed by a considerable increase of the corpuscles in the vessels, with the transudation of serum into the surrounding tissues, may be regarded as an explanation of the moderate increase in the cases accompanied by anasarca, but it has no special bearing upon cases of congenital cyanosis in which there is no drain of flaid into the tissues. It may possibly be held that in such cases the lymph vessels are unusually active, and that the fluid constituents of the blood are as rapidly absorbed as they transude. Such an opinion can scarcely be seriously entertained. The backward pressure on the venous system which causes the transudation must tell on both terminations of the absorbents. It may be admitted freely that the increased pressure on the peripheral veins may tend to raise that impelling the fluids into the commencement of the lymphatics, but it must not be forgotten that an elevation of pressure in the great reins will hinder the return of the lymph by pressing upon the openings of the lymph vessels into the veins. It is probable that the increase in the red corpuscles may be to some extent compensatory in cases of cyanosis. To say this, however, is not enough; it affords no rational explanation of the process by which the increase is brought about. Nature does not work by such direct methods as would require to be invoked if the increase of the corpuscles were regarded as a simple compensatory change, balancing the diminished power of oxygenation. Compensation in valvular lesions, for example, is produced by the definite structural changes constituting hypertrophy, caused by increase of work, and compensation in cyanosis must have some reasonable explanation also. It seems to me that such an explanation may be found in a consideration of the functions of the red corpuscles under changed conditions. In venous stasis the corpuscles are insufficiently oxygenated, they cannot perform such an active part as oxygen carriers, and they cannot yield so much oxygen to the tissues. It must further be remembered that in cyanosis there is less metabolism in the tissues, and therefore less waste produced. In a word, the functions of the corpuscles being lessened, the tear and wear which they undergo is reduced, and the duration of their individual existence increased. The number of the corpuscles must in this way be proportionately augmented, and this must lead to the numerical increase, as well as to the high percentage of bæmoglobin, until a balance is struck between the production and the destruction of the blood-corpuscles.

It is a pleasure to express my warm thanks to Dr. J. G Cattanach, resident medical officer to the Deaconness Hos pital, for his unwearied assistance in the investigation of the blood in the cases to which reference bas been made and in the examination of their clinical details.

Bibliography.-Toeniessen: Ueber Blatkörperchenzählung bei gesunden und kranken Menschen. Erlangen, 1881.Carmichael : Edinburgh Hospital Reports, vol. ii., 1894.Morgagni : De Sedibas et Caasis Morborum, tom. i., Venice, 1761.-Hanter : Medical Observations and Enquiries, vol. vi., London, 1783.-Schneider : Ueber die Morphologischen Verhältnisse des Blutes bei Herzkrankheiten und bei Carcinom. Berlin, 1888.-Malassez : Archives de Pbysiologie, ii. série, tome i., 1874.-Penzoldt : Berliner Klinische Wochenschrift, 1881.- Cobnheim: Archiv für physiologische und patbologische Anatomie und für klinische Medicin, 41. Band, 1867. Edinburgh. 